\title{
Prospective Nanotechnology-Based Strategies for Enhanced Intra- and Transdermal Delivery of Antifungal Drugs
}

\author{
Ekaterina V. Lengert ${ }^{a} \quad$ Ekaterina E. Talnikova $^{b}$ Valery V. Tuchin ${ }^{c, d}$ \\ Yulia I. Svenskaya ${ }^{a}$ \\ aEducational and Research Institute of Nanostructures and Biosystems, Saratov State University, \\ Saratov, Russia; 'Department of Dermatovenereology and Cosmetology, Saratov State Medical University, \\ Saratov, Russia; 'Research-Educational Institute of Optics and Biophotonics, Saratov State University,

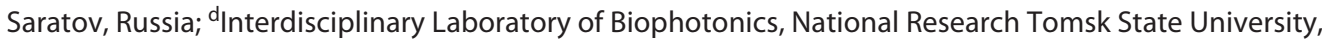 \\ Tomsk, Russia
}

\section{Keywords}

Antifungal agents - Dermatophytes - Antimycotics ·

Transdermal drug delivery

\begin{abstract}
Topical therapy of superficial fungal infections allows the prevention of systemic side effects and provides drug targeting at the site of disease. However, an appropriate drug concentration in these sites should be provided to ensure the efficacy of such local treatment. The enhancement of intra- and transdermal penetration and accumulation of antifungal drugs is an important aspect here. The present overview is focused on novel nano-based formulations served to improve antimycotic penetration through the skin. Furthermore, it summarizes various approaches towards the stimulation of drug penetration through and into the stratum corneum and hair follicles, which are considered to be promising for the future improvement of superficial antifungal therapy as providing the drug localization and prolonged storage property at the targeted area.
\end{abstract}

(c) 2020 S. Karger AG, Basel

\section{Introduction}

Over recent decades, there has been a significant spread of fungal diseases $[1,2]$. Dermatophytes are one of the most common etiological agents of skin mycoses [3, 4]. The development of various antifungal agents has already significantly increased the ability to combat skin mycosis. However, the search for new approaches towards the enhancement of antifungal therapy efficiency remains relevant. Over the last decades, the elaboration of different strategies aimed at optimization of the antimycotic action while minimizing the side effects associated with its absorption through the skin [5-9]. Novel drugs and delivery systems that improve the safety of mycosis treatment were proposed [10-13]. It is known that the nature of drug carriers used in topical preparations significantly affects the speed and the depth of drug penetration into and through the skin $[14,15]$. Systems such as micelles, liposomes, submicron emulsions, and solid lipid or polymer nanoparticles have been suggested as antifungal carriers with enhanced percutaneous absorption ability $[9,10,12,13]$. Although due to the skin's barrier functions, their penetration into the healthy intact skin

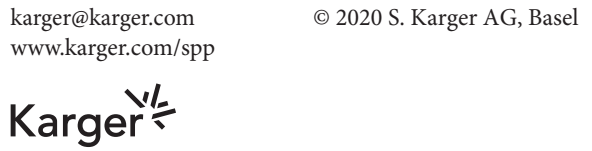

Ekaterina V. Lengert or Yulia I. Svenskaya

Institute of Nanostructures and Biosystems, Saratov State University 83 Astrakhanskaya Street

Saratov 410012 (Russian Federation)

Lengertkatrin@mail.ru or svenskaya@info.sgu.ru 
remains limited in some cases. These systems can be successfully applied for drug delivery through the damaged skin in order to treat diseases such as atopic dermatitis or superficial mycoses.

Aside from appropriate carrying system development, there are a number of chemical, biochemical, and physical approaches are elaborated in order to improve the efficacy of transdermal drug permeation [16]. Different solvents, surfactants, and peptides may interact with the lipid matrix of the stratum corneum and increase its permeability for drug molecules [17-21]. Various physical methods such as stripping, iontophoresis, ultrasound, intradermal injection and microinjection, and thermal ablation are successfully applied to increase the transdermal delivery of the drug either alone or immobilized into the carriers $[16,22]$. This review is focused on the use of different nanoparticles for drug delivery through and into the skin in terms of treatment of fungal infections and on the application of various physical and chemical influences enhancing the transdermal drug penetration that could be adopted for use in antifungal therapy.

\section{Basic Principles of Antifungal Therapy}

Etiotropic treatment of fungal infections is based on the usage of systemic or topical antifungal formulations $[6,7]$. Systemic therapy is usually applied for the treatment of either deep mycosis or extensive/chronic superficial ones as it may cause systemic toxicity [23]. Systemic antifungals such as Amphotericin B formulations, echinocandins, and triazoles often cause hepatic toxicity [24]. The other common adverse effects include nephrotoxicity, neurotoxicity, haematological side effects, and very rarely, fever, chills, arrhythmia, hypotension, and respiratory distress [25]. Moreover, systemic therapy does not allow for immediate local accumulation of high antifungal drug concentrations.

Common superficial fungal infections are treated with topical medications which provide the accumulation of antifungal drug in skin [8]. Such therapy allows the prevention of the systemic side effects mentioned above. Furthermore, it enables the avoidance of the firstpass liver effect. The main adverse effects caused by the topical antifungals are associated with allergic reactions in skin (dryness, redness, burning, itching, and irritation).

To be effective against superficial fungal infections, an antifungal agent must reach the stratum corneum, hairs or nails to target the pathogen in adequate concentration, and persist at this location long enough to inhibit the fungal pathogen. The achieved intradermal drug concentration depends on administration route, duration of the contact, and ability of the antifungal molecules to penetrate into the tissue [8]. The latter is defined by the molecular weight, viscosity, hydrophobicity, and acidity of the formulation. Although the topical antifungal drugs cover a broad range of therapeutic indications and have various molecular structures, they are generally highly lipophilic and have poor aqueous solubility (e.g., clotrimazole, miconazole, itraconazole, terbinafine, etc.) and therefore capable of penetration into the lipidic stratum corneum [8]. The rate and extent of delivery here should be appropriate to achieve the required local therapeutic concentration. Moreover, large antifungal molecules show poor transdermal penetration, even if they are lipophilic. Poor penetration into the skin limits local bioavailability and drug efficacy and thus causes the relapse of infections and requires frequent administration.

Furthermore, regardless of the formulation type, the penetration of topical agents in hyperkeratotic lesions is often limited $[6,15]$. For this reason, the majority of modern transdermal drugs used in their treatment do not require removal from the infected area after their application.

By this means, the topical antifungal drug delivery provides a major challenge for its optimization. The skin represents a target for the therapy, as well as a principal barrier for transdermal delivery of the topically applied drug.

\section{Penetration Routes of Topically Applied Drugs}

Topically applied drugs penetrate through the skin via either transepidermal or transappendageal route. The transepidermal pathway involves the transport of molecules through the stratum corneum, which represents a multilayered and multicellular barrier. It provides a protective barrier function against external actions $[16,26]$. Hydrophilic or polar solutes penetrate through corneocytes (intracellular route), while lipophilic or non-polar ones can diffuse via intercellular spaces including continuous lipid matrix. Despite major research and development efforts in topical antifungal delivery systems and their advantages, design of a delivery system allowing one to overcome the limitations associated with transepidermal penetration remains actual. 
The alternative, transappendageal delivery route involves cargo permeation via sebaceous and sweat glands, hair funnels, and follicles. The latter can serve as an efficient reservoir extended deep into the skin tissue with systemic drug uptake provided by a dense capillary network of the dermal vasculature $[27,28]$. In order to improve the penetration of topically applied drugs through these different skin sites, various transdermal drug delivery systems (nano- and microcarriers) and enhancement strategies (physical, chemical and biochemical enhancers) are elaborated.

\section{Particulate Intra- and Transdermal Delivery Systems}

Nano- and micron-sized carriers have been successfully used to increase penetration of drugs or vaccines into the skin, to target them to the specific areas of skin, as well as to control the subsequent drug release in situ. In particulate formulations, drug penetration into skin is governed by physico-chemical properties of the carrier such as size [29], surface area [30], charge [31], $\mathrm{pH}$, and solubility [32], and depends on the chemical composition of the carrier and solvent nature as well $[14,33,34]$. Among these factors, the influences of the size and the charge have been widely studied. Particles of approximately $300-600 \mathrm{~nm}$ in size exhibit the deepest penetration into hair follicles, where they can be stored for a significantly longer period than in the stratum corneum [35]. Moreover, the skin penetration and biological activity depend also on the morphology of nanoparticles [36], biological adhesiveness [37], and degradation in vivo [38].

Various carrying systems were proposed for improving the bioavailability, and sustained and controlled release of the loaded drug. Lipid-based particles [39-41] and nanoemulsions [42] are the most well-established ones. The usage of these systems allows the maintaining of the localized therapeutic effect and provides the enhancement of the drug accumulation in different skin sites. Nevertheless, some difficulties arise when liposomes are applied due to their low stability. Biodegradable polymeric [43-45] and inorganic porous [46-49] carriers represent the alternative encapsulation system that allows one to increase the penetration/permeation of drugs throughout the skin appendages. The other approaches proposed for transdermal drug delivery include the use of quantum dots [50], liquid crystalline nanoparticles [51], silk fibroin nanocarriers [52] etc.

Enhanced Transdermal Delivery of Antifungal Drugs

\section{Nanocarriers for Intradermal Permeation and Antimycotic Activity Enhancement of Topical Antifungals}

Transdermal delivery of nanoparticles has gained a great interest in topical antifungal therapy provided by high drugs penetration rate and controllability of gradual or triggered encapsulated payload release. Active development of various nano- and micron-sized systems for transdermal drug delivery opens up the possibilities for antifungal therapy improvement [53]. Serving as a local (isolated) drug depot and providing a mechanism for controlled release, such systems can deliver high topical concentrations of drugs without pronounced systemic spread [54]. Thus, systems such as polymeric films [55], nano- and microemulsions [56], vesicular carriers [57] (including liposomes [58], ethosomes [59], transethosomes [60], and niosomes [61]), solid lipid [62] and polymeric particles [63], and porous inorganic carriers [64, 65] were proposed and investigated for antifungal agents' penetration promotion.

Ethosomal gel of econazole nitrate was found to have outstanding potential to serve as a topical delivery system, enabling controlled drug release, providing a better antifungal effect. Optimized ethosomes with vesicle size of 202 $\pm 5 \mathrm{~nm}$ and entrapment efficiency of $81 \%$ were formulated as Carbopol gels with varied permeation enhancers and compared with liposomal and hydroethanolic gels [66]. Nystatin antifungal activity against Candida albicans microorganism was enhanced by its encapsulation into nanostructured lipid carriers as compared to the drug solution and to commercially available Nystatin cream [67].

Deformable membrane vesicles preparation for topical delivery of griseofulvin as a potential system for dermatophytosis treatment was proposed $[68,69]$. The systems based on solid lipid nanoparticles with a controlled release property [70] and nanostructured lipid carrier [71] were formulated for terbinafine hydrochloride. Solid lipid nanoparticles were also applied for Amphotericin B immobilization [72]. Enhanced antifungal activity with low skin irritation was demonstrated as a result of their topical deposition. Dendrimer-based carriers were tested for Amphotericin B delivery showing a high antiparasitic activity in vitro against parasite-infected macrophage cell lines and in vivo on infected mice due to the ability of drug targeting to macrophages [73]. Synergistic fungicidal effect of low-frequency and low-intensity ultrasound combined with a treatment of Amphotericin B-loaded PLGA nanoparticles against $C$. albicans was demonstrated in vitro [74].

Skin Pharmacol Physiol 2020;33:261-269 


\section{Physical and Chemical Strategies to Enhancement of Intra- and Transdermal Drug Delivery}

Aside from the development and optimization of antifungal particulate delivery systems, significant efforts are expended on the elaboration of novel approaches to increase skin permeability and therefore to enhance transdermal drug delivery [16]. These strategies can be divided into chemical (usage of special solvents or surfactants), biochemical (the use of metabolic inhibitors), and physical approaches. There are plenty of physical methods, commonly requiring the use of special devices, which allow one to significantly expand the spectrum of drugs that can be administered transdermally (including watersoluble molecules and macromolecules). Such methods include stripping techniques, sono- or iontophoresis, heating, electroporation, mechanical abrasion, thermal ablation, and microneedle usage [22].

The most established and less invasive methods for enhanced drug penetration through the skin barrier involve either removal of outermost skin layer achieved by the peeling tape (tape stripping) or usage of various chemical enhancers, such as dimethylsulphoxide, propylene glycol, ethanol, oleic acid, EDTA, sodium glycocholate and related cholates, Tween 20 (a non-ionic polysorbate surfactant), Brij 35 (polyoxyethylene lauryl ether), saponins, and bile salts [75-77]. Generally, penetration enhancers are small molecules that temporarily soften the bond between the adjacent cells of the corneal epithelium (EDTA) or increase the fluidity of membranes (cholates) [76]. It was demonstrated that chemical enhancers can increase dermal penetration of various antifungal drugs. Thus for example, application of $50 \%$ ethanol and $50 \%$ isopropyl myristate formulation containing $5 \%$ oleic acid significantly enhanced in vivo availability of topical terbinafine [78]. Enhancement of antimycotic delivery using various solvents (dimethyl sulfoxide, methanol), enzymes, hydrogen peroxides, etc. were demonstrated for onychomycosis treatment as well $[79,80]$.

Moreover, improved skin permeation and accumulation of antifungals (ketoconazole, terbinafine) under combined application of chemical enhancers (essential oils, such as eucalyptus and nigella, or alcohols, such as nerolidol) and carrying vehicles were shown [81-83]. Different pretreatments such as hair plucking [84], hot or cold waxing [85], and cyanoacrylate stripping [86] are used to create channels in the skin before the drug application. In terms of antifungal treatment, the pretreatment techniques are represented by nail drilling proving the formation of tunnels throughout the nail plate to aug- ment delivery and efficacy of topical antifungals to the site of onychomycosis [87].

Ultrasonic treatment (sonophoresis, phonophoresis) is one of the less invasive physical enhancers $[88,89]$. It is effectively utilized for enhanced intra- and transdermal delivery of bioactive molecules [90] and particulate systems [47]. Such ultrasonic treatment of skin at frequencies higher than $0.7 \mathrm{MHz}$ gives rise to pressure changes in the medium, forming cavitation bubbles inside the inherent cavities represented by hair follicle shafts and sweat glands [91]. Bubbles oscillation in the follicles push the particle suspension down the follicle. It was shown, that application of $1 \mathrm{MHz}$ ultrasound at a power density of 2 $\mathrm{W} / \mathrm{cm}^{2}$ did not induce adverse effects on rat skin [92]. Prolongation of the enhanced permeability time window allows for the stepwise application of drugs or vaccines [93]. Ultrasonication can also be coupled with other methods. Thus, enhanced transdermal delivery of solid nanoparticles by simultaneous application of ultrasound and various chemical enhancers was demonstrated [94, 95].

Iontophoretic delivery is another effective non-invasive approach for therapeutic drug delivery $[96,97]$. Generally, transdermal iontophoresis creates a small electric current $\left(0.1-0.5 \mathrm{~mA} / \mathrm{cm}^{2}\right)$ in the skin to induce transdermal molecular transport, enhancing drug transportation by electrorepulsion and electro-osmosis. At neutral $\mathrm{pH}$, the skin is negatively charged and cation-permselective [98]. Thus, the current passage causes a convective solvent flow from anode to cathode, facilitating cation transport and enabling the enhanced transdermal transport of neutral, polar solutes. Relative electrorepulsion and electro-osmosis effects depend on the physico-chemical and electrical characteristics of the membrane and permanent. In addition, the negative charge of the skin can be reduced, neutralized, or even reversed by the iontophoresis of certain cationic, lipophilic species [99].

Simultaneous application of sonophoresis and iontophoresis is also discussed [100-102]. The synergistic effect of their application is demonstrated for transdermal delivery of various cosmeceutical drugs using a Franz diffusion cell. Such a combined strategy is advantageous as it declines the energy density and thereby reduces the skin irritation [100].

Phono- and iontophoresis were successfully applied for transungual delivery of antimycotics (e.g., terbinafine and ciclopirox) allowing the significant enhancement of their penetration into nail plates [103, 104]. Heating is another physical approach allowing one to improve the delivery profile of topical medicaments $[105,106]$. The 


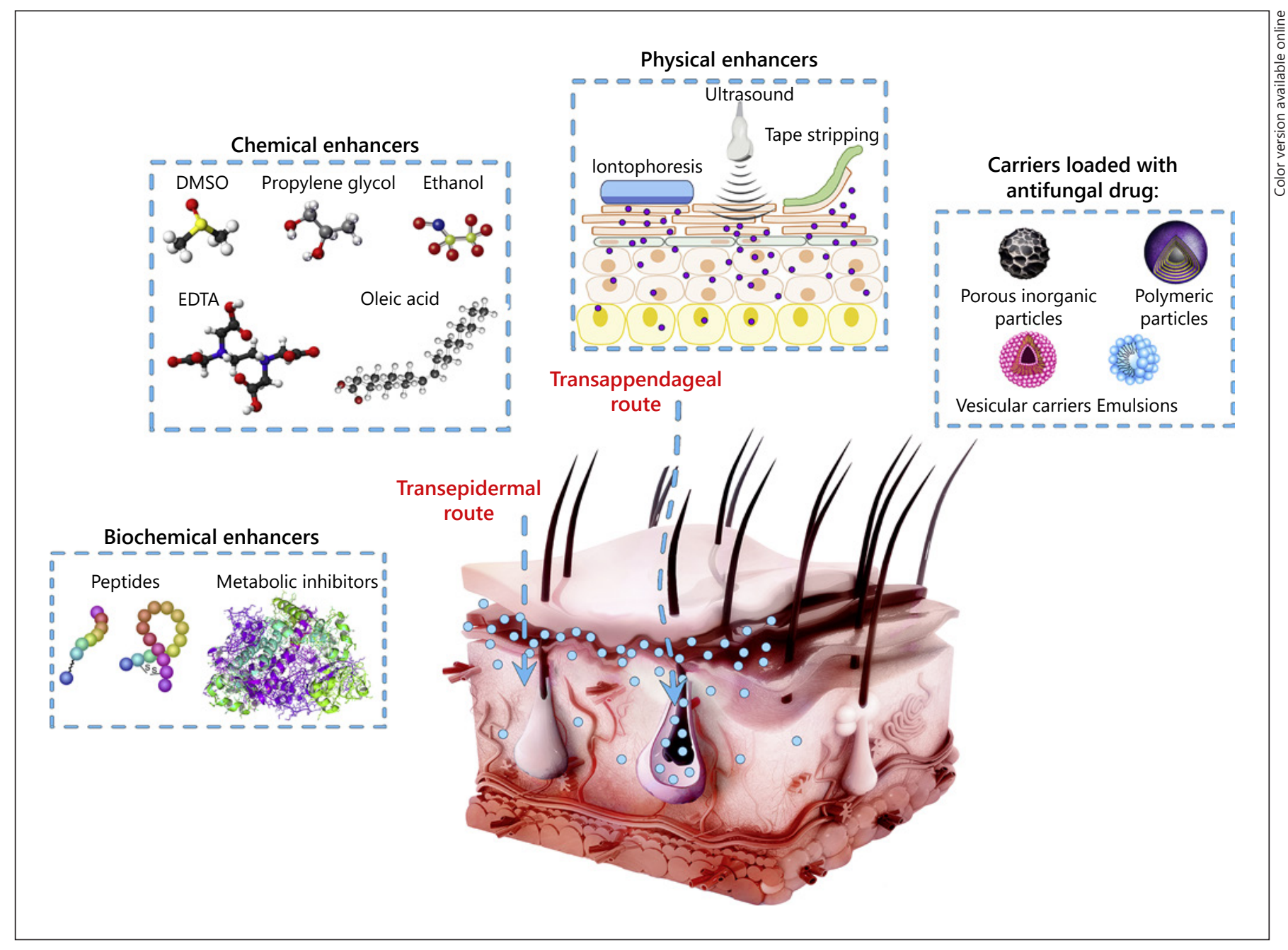

Fig. 1. Promising strategies for enhanced intra- and transdermal delivery of antifungals. Different nanoparticles that are used to deliver antifungal drug through and into the skin, and various physical, chemical, and biochemical enhancers that can be adopted for use in antifungal therapy.

heat-enhanced effect is generally attributed to both an increase in drug diffusion in the vehicle and skin, and to an increase in skin lipid fluidity. Furthermore, the skin temperature rise increases its blood supply that also plays an important role in enhancing the transdermal delivery of a topically applied compound [106].

Microporation is one of the most common invasive physical methods applied for the skin barrier removal. Such a method allows the formation of micropores or even microchannels in the skin by the usage of microneedles fabricated of different materials and geometries [107, 108] or laser and radiofrequency ablations, which allows for further transferring of water-soluble molecules and macromolecules $[106,109]$, as well as particulate systems [110-114]. Such techniques enable the delivery of much larger molecules with much greater fluxes into the skin than other methods and therefore are extensively developed for delivery of insulin [115], hormones [116], vaccines [117], etc.

Although the formation of micron-scale holes within the stratum corneum is a prospective and successfully applied approach towards the transdermal drug transportation, its adaptation for antifungal treatment of skin appears unpromising as this procedure is invasive. Furthermore, it should be mentioned here that microneedling treatment results in the expression of various genes related to epidermal differentiation, inflammation, and dermal remodelling [118]. Thus, microneedles possess own pharmacological activity which may interact with the antimycotic compound. 
Combined application of the most efficient physical methods with various nanocarriers was also investigated demonstrating its superiority in drug penetration enhancement compared to their single use [119]. Thus for example, a particulate drug delivery system based on the use of porous biodegradable carriers appeared beneficial when applied topically together with sonophoresis [47, 120]. Meanwhile, no evidence of systemic toxicity enhancement was indicated. The proposed system provided the transportation of immobilized drug along the entire depth of hair follicles, its intrafollicular accumulation, and prolonged storage. Such an approach was successfully applied for transdermal delivery of griseofulvin antifungal drug as well [65].

\section{Conclusion}

Encapsulation of antifungal drugs into various nanoand micron-sized carriers allows for further enhancement of mycosis treatment, particularly therapeutic activity and prolonged effect while enabling triggered release by specific chemical and/or pathophysiologic stimuli. Furthermore, the usage of such systems allows the maintaining of the localized therapeutic effect and provides the enhancement of the drug accumulation in skin. By increasing the efficiency of transdermal delivery of antimycotics, one can enhance its therapeutic efficacy.

In addition, the adaptation of different chemical, biochemical, and physical delivery-enhancing techniques for the use in antifungal treatment renders promising. These methods can allow one to overcome challenging limitations such as low bioavailability of many peroral medicaments and narrow range of choice of the antifungal formulations. Thus for example, plasters, chemical enhancers, iontophoresis, and ultrasonication may open up new perspectives here as they provide the transdermal transportation of low-soluble molecules and macromolecules. The usage of various chemical enhancers, such as dimethylsulphoxide, propylene glycol etc., alone or in combina- tion with physical enhancers is a promising approach to be applied in dermatological practice as well as may provide localization and increased topical concentration of antifungal drug together with prolonged exposure at the targeted site.

Reporting here on the most interesting and prospective, from our point of view, strategies which either aimed at or can be adopted for optimization of topical antifungal drug delivery (Fig. 1), we hope to encourage other researchers to look beyond classical methods and put into practice the novel ones. However, it should be taken into consideration that despite potentially decreased drug toxicity due to increased skin targeting, extensive and accurate chronic toxicity studies should be done before the translation of any novel treatment method to humans.

\section{Acknowledgement}

We would like to thank A.V. Ermakov for the fruitful discussion.

\section{Conflict of Interest Statement}

The authors have no conflicts of interest to declare.

\section{Funding Sources}

The study was supported by the Russian Science Foundation (Project No. 17-73-20172)

\section{Author Contributions}

Investigation and writing - Ekaterina V. Lengert and Yulia I. Svenskaya. Design of the figure - Ekaterina V. Lengert. Conceptualization - Yulia I. Svenskaya. Editing, reviewing, and improving the manuscript - Yulia I. Svenskaya, Ekaterina E. Talnikova, and Valery V. Tuchin. All authors have read and approved the final manuscript.

\section{References}

1 Denning DW. Calling upon all public health mycologists: to accompany the country burden papers from 14 countries. Eur J Clin Microbiol Infect Dis. 2017;36(6):923-4.

2 Bongomin F, Gago S, Oladele R, Denning D. Global and multi-national prevalence of fungal diseases-estimate precision. J Fungi. 2017; 3(4):57.
3 Ginter-Hanselmayer G, Nenoff P. Clinically relevant mycoses dermatomycoses. Clinically relevant mycoses. Cham: Springer International Publishing; 2019. p. 145-76.

4 Faway É, Lambert de Rouvroit C, Poumay Y. In vitro models of dermatophyte infection to investigate epidermal barrier alterations. Exp Dermatol. 2018;27:915-22.
5 Hart R, Bell-Syer SE, Crawford F, Torgerson DJ, Young P, Russell I. Systematic review of topical treatments for fungal infections of the skin and nails of the feet. BMJ. 1999;319(7202): 79-82.

6 Gupta AK, Cooper EA. Update in antifungal therapy of dermatophytosis. Mycopathologia. 2008;166(5-6):353-67. 
7 Nenoff P, Krüger C, Paasch U, Ginter-Hanselmayer G. Mycology: an update part 3: dermatomycoses: topical and systemic therapy. J Dtsch Dermatol Ges. 2015;13(5):387-411.

8 Kaur IP, Kakkar S. Topical delivery of antifungal agents. Expert Opin Drug Deliv. 2010; 7(11):1303-27.

9 Kumar L, Verma S, Bhardwaj A, Vaidya S, Vaidya B. Eradication of superficial fungal infections by conventional and novel approaches: a comprehensive review. Artif Cells Nanomed Biotechnol. 2014;42(1):32-46.

10 Basak A, Chakraborty R, Mandal SMM. Recent trends in antifungal agents and antifungal therapy. New Delhi, India: Springer; 2016.

11 Scorzoni L, de Paula e Silva AC, Marcos CM, Assato PA, de Melo WC, de Oliveira HC, et al. Antifungal therapy: new advances in the understanding and treatment of mycosis. Front Microbiol. 2017;8:36.

12 Bangia R, Sharma G, Dogra S, Katare OP. Nanotechnological interventions in dermatophytosis: from oral to topical, a fresh perspective. Expert Opin Drug Deliv. 2019;16(4): 377-96.

13 Nicola AM, Albuquerque P, Paes HC, Fernandes L, Costa FF, Kioshima ES, et al. Antifungal drugs: new insights in research \& development. Pharmacol Ther. 2019;195:21-38.

14 Papakostas D, Rancan F, Sterry W, BlumePeytavi U, Vogt A. Nanoparticles in dermatology. Arch Dermatol Res. 2011;303(8):53350.

15 Palmer BC, DeLouise LA. Nanoparticle-enabled transdermal drug delivery systems for enhanced dose control and tissue targeting. Molecules. 2016;21(12):1719.

16 Prausnitz MR, Elias PM, Franz TJ, Schmuth M, Tsai JC, Menon GKFK. Skin barrier and transdermal drug delivery. Dermatology. 2012;3:2065-70.

17 Barry BW. Mode of action of penetration enhancers in human skin. J Control Release. 1987;6(1):85-97.

18 Lane ME. Skin penetration enhancers. Int J Pharm. 2013;447(1-2):12-21.

19 Kumar S, Zakrewsky M, Chen M, Menegatti S, Muraski JA, Mitragotri S. Peptides as skin penetration enhancers: mechanisms of action. J Control Release. 2015;199:168-78.

20 Haque T, Talukder MMU. Chemical enhancer: a simplistic way to modulate barrier function of the stratum corneum. Adv Pharm Bull. 2018;8(2):169-79.

21 Do N, Weindl G, Grohmann L, Salwiczek M, Koksch B, Korting HC, et al. Cationic membrane-active peptides: anticancer and antifungal activity as well as penetration into human skin. Exp Dermatol. 2014;23(5):326-31.

22 Engelke L, Winter G, Hook S, Engert J. Recent insights into cutaneous immunization: how to vaccinate via the skin. Vaccine. 2015; 33(37):4663.

23 Downes KJ, Fisher BT, Zane NR. Administration and dosing of systemic antifungal agents in pediatric patients. Paediatr Drugs. 2020; 22(2):165-88.
24 Kyriakidis I, Tragiannidis A, Munchen S, Groll AH. Clinical hepatotoxicity associated with antifungal agents. Expert Opin Drug Saf. 2017 Feb;16(2):149-65.

25 Seyedmousavi S, Rafati H, Ilkit M, Tolooe A, Hedayati MT, Verweij P. Systemic antifungal agents: current status and projected future developments. Methods Mol Biol. 2017;1508: 107-39.

26 Jepps OG, Dancik Y, Anissimov YG, Roberts MS. Modeling the human skin barrier: towards a better understanding of dermal absorption. Adv Drug Deliv Rev. 2013;65(2): $152-68$.

27 Lademann J, Knorr F, Richter H, Jung S, Meinke MC, Rühl E, et al. Hair follicles as a target structure for nanoparticles. J Innov Opt Health Sci. 2015;8:1-8.

28 Knorr F, Lademann J, Patzelt A, Sterry W, Blume-Peytavi U, Vogt A. Follicular transport route: research progress and future perspectives. Eur J Pharm Biopharm. 2009;71(2): 173.

29 Patzelt A, Richter H, Knorr F, Schäfer U, Lehr CM, Dähne L, et al. Selective follicular targeting by modification of the particle sizes. J Control Release. 2011;150(1):45-8.

30 Mahant S, Kumar S, Nanda S, Rao R. Microsponges for dermatological applications: perspectives and challenges. Asian J Pharm Sci. 2020 May;15(3):273-91.

31 Gillet $A$, Compère $P$, Lecomte $F$, Hubert $P$, Ducat E, Evrard B, et al. Liposome surface charge influence on skin penetration behaviour. Int J Pharm. 2011;411(1-2):223-31.

32 Vaidyanathan R, Chaubal MG, Vasavada RC. Effect of $\mathrm{pH}$ and solubility on in vitro skin penetration of methotrexate from a $50 \% \mathrm{v} / \mathrm{v}$ propylene glycol-water vehicle. Int J Pharm. 1985;25:85-93.

33 Vogt A, Wischke C, Neffe AT, Ma N, Alexiev $\mathrm{U}$, Lendlein A. Nanocarriers for drug delivery into and through the skin: do existing technologies match clinical challenges? J Control Release. 2016;242:3-15.

34 Liang XW, Xu ZP, Grice J, Zvyagin AV, Roberts MS, Liu X. Penetration of nanoparticles into human skin. Curr Pharm Des. 2013, 19(35):6353-66.

35 Lademann J, Richter H, Schanzer S, Knorr F, Meinke M, Sterry W, et al. Penetration and storage of particles in human skin: perspectives and safety aspects. Eur J Pharm Biopharm. 2011;77(3):465.

36 Tadros AR, Romanyuk A, Miller IC, Santiago A, Noel RK, O'Farrell L, et al. STAR particles for enhanced topical drug and vaccine delivery. Nat Med. 2020;26(3):341-7.

37 Deng Y, Ediriwickrema A, Yang F, Lewis J, Girardi M, Saltzman WM. A sunblock based on bioadhesive nanoparticles. Nat Mater. 2015;14(12):1278-85.

38 Larese Filon F, Mauro M, Adami G, Bovenzi M, Crosera M. Nanoparticles skin absorption: new aspects for a safety profile evaluation. Regul Toxicol Pharmacol. 2015;72(2):31022.
39 Liu R(R), Cannon JB, Paspal SYL. Water-insoluble drug formulation. 2nd ed. CRC Press; 2008.

40 Moradi L, Javanmardi S, Abolmaali S, Mohammadi Samani S. Passive enhancement of transdermal drug delivery: lipid-based colloidal carriers as an emerging pharmaceutical technology platform. Trends Pharmacol Sci. 2019;5:25-40.

41 Franzè S, Musazzi UM, Cilurzo F. Lipid vesicles for (trans)dermal administration. Nanomaterials for Clinical Applications. Elsevier; 2020. p. 71-98.

42 Rai VK, Mishra N, Yadav KS, Yadav NP. Nanoemulsion as pharmaceutical carrier for dermal and transdermal drug delivery: formulation development, stability issues, basic considerations and applications. J Control Release. 2018;270:203-25.

43 Rancan F, Blume-Peytavi U, Vogt A. Utilization of biodegradable polymeric materials as delivery agents in dermatology. Clin Cosmet Investig Dermatol. 2014;7:23.

44 Takeuchi I, Kagawa A, Makino K. Skin permeability and transdermal delivery route of 30-nm cyclosporin A-loaded nanoparticles using PLGA-PEG-PLGA triblock copolymer. Colloids Surf. 2020;600:124866.

45 Praveen A, Aqil M. Transdermal delivery of Chitosan-based systems. Functional Chitosan. Singapore: Springer; 2019. p. 75-106.

46 Rancan F, Gao Q, Graf C, Troppens S, Hadam S, Hackbarth S, et al. Skin penetration and cellular uptake of amorphous silica nanoparticles with variable size, surface functionalization, and colloidal stability. ACS Nano. 2012; 6(8):6829-42.

47 Svenskaya YI, Genina EA, Parakhonskiy BV, Lengert EV, Talnikova EE, Terentyuk GS, et al. A simple non-invasive approach toward efficient transdermal drug delivery based on biodegradable particulate system. ACS Appl Mater Interfaces. 2019;11(19): 17270-82.

48 Arriagada F, Nonell S, Morales J. Silica-based nanosystems for therapeutic applications in the skin. Nanomedicine. 2019;14(16):224367.

49 Nafisi S, Schäfer-Korting M, Maibach HI Perspectives on percutaneous penetration: silica nanoparticles. Nanotoxicology. 2015; 9(5):643-57.

50 Mortensen LJ, Oberdörster G, Pentland AP, DeLouise LA. In vivo skin penetration of quantum dot nanoparticles in the murine model: the effect of UVR. Nano Lett. 2008;8: 2779-87.

51 Elgindy NA, Mehanna MM, Mohyeldin SM. Self-assembled nano-architecture liquid crystalline particles as a promising carrier for progesterone transdermal delivery. Int J Pharm. 2016;501(1-2):167-79.

52 Takeuchi I, Shimamura Y, Kakami Y, Kameda T, Hattori K, Miura S, et al. Transdermal delivery of 40-nm silk fibroin nanoparticles. Colloids Surf B Biointerfaces. 2019;175:5648.
Enhanced Transdermal Delivery of Antifungal Drugs
Skin Pharmacol Physiol 2020;33:261-269 DOI: $10.1159 / 000511038$ 
53 Renzi DF, de Almeida Campos L, Miranda EH, Mainardes RM, Abraham W-R, Grigoletto DF, et al. Nanoparticles as a tool for broadening antifungal activities. Curr Med Chem. 2020;27.

54 Gupta M, Vyas SP. Development, characterization and in vivo assessment of effective lipidic nanoparticles for dermal delivery of fluconazole against cutaneous candidiasis. Chem Phys Lipids. 2012;165(4):454-61.

55 Salama M, Mahdy M, Mohamed A, Mohamed A, Keleb E, Omar A, et al. Formulation and evaluation of ketoconazole polymeric films for topical application. J App Pharm Sci. 2015;5:028-32.

56 Qurt MS, Esentürk İ, Birteksöz Tan S, Erdal MS, Araman A, Güngör S. Voriconazole and sertaconazole loaded colloidal nano-carriers for enhanced skin deposition and improved topical fungal treatment. J Drug Deliv Sci Technol. 2018;48:215-22.

57 Verma S, Utreja P. Vesicular nanocarrier based treatment of skin fungal infections: potential and emerging trends in nanoscale pharmacotherapy. Asian J Pharm Sci. 2019;14(2):117-29.

58 Elmoslemany RM, Abdallah OY, El-Khordagui LK, Khalafallah NM. Propylene glycol liposomes as a topical delivery system for miconazole nitrate: comparison with conventional liposomes. AAPS PharmSciTech. 2012; 13(2):723-31.

59 Faisal W, Soliman GM, Hamdan AM. Enhanced skin deposition and delivery of voriconazole using ethosomal preparations. J Liposome Res. 2018;28(1):14-21.

60 Nayak D, Tawale RM, Aranjani JM, Tippavajhala VK. Formulation, optimization and evaluation of novel ultra-deformable vesicular drug delivery system for an anti-fungal drug. AAPS PharmSciTech. 2020;21(5):140.

61 Osanloo M, Assadpour S, Mehravaran A, Abastabar M, Akhtari J. Niosome-loaded antifungal drugs as an effective nanocarrier system: a mini review. Curr Med Mycol. 2018; $4(4): 31-6$

62 Al-Maghrabi PM, Khafagy ES, Ghorab MM, Gad S. Influence of formulation variables on miconazole nitrate-loaded lipid based nanocarrier for topical delivery. Colloids Surf B Biointerfaces. 2020;193:111046.

63 Alhowyan AA, Altamimi MA, Kalam MA, Khan AA, Badran M, Binkhathlan Z, et al. Antifungal efficacy of Itraconazole loaded PLGA-nanoparticles stabilized by vitamin-E TPGS: in vitro and ex vivo studies. J Microbiol Methods. 2019;161:87-95.

64 Gusliakova O, Verkhovskii R, Abalymov A Lengert E, Kozlova A, Atkin V, et al. Transdermal platform for the delivery of the antifungal drug naftifine hydrochloride based on porous vaterite particles. Mater Sci Eng C. 2021;119:111428. https://doi.org/10.1016/j. msec.2020.111428

65 Lengert E, Verkhovskii R, Yurasov N, Genina E, Svenskaya Y. Mesoporous carriers for transdermal delivery of antifungal drug. $\mathrm{Ma}-$ ter Lett. 2019;248:211-3.
66 Verma P, Pathak K. Nanosized ethanolic vesicles loaded with econazole nitrate for the treatment of deep fungal infections through topical gel formulation. Nanomedicine. 2012; 8(4):489-96.

67 Khalil R. Formulation and characterization of nystatin-loaded nanostructured lipid carriers for topical delivery against cutaneous candidiasis. Br J Psychol. 2014;4(4):490-512.

68 Aggarwal N, Goindi S. Preparation and evaluation of antifungal efficacy of griseofulvin loaded deformable membrane vesicles in optimized guinea pig model of Microsporum canis: dermatophytosis. Int J Pharm. 2012 437(1-2):277-87.

69 Marto J, Vitor C, Guerreiro A, Severino C, Eleutério C, Ascenso A, et al. Ethosomes for enhanced skin delivery of griseofulvin. Colloids Surf B Biointerfaces. 2016;146:616-23.

70 Vaghasiya H, Kumar A, Sawant K. Development of solid lipid nanoparticles based controlled release system for topical delivery of terbinafine hydrochloride. Eur J Pharm Sci. 2013;49(2):311-22

71 Gaba B, Fazil M, Khan S, Ali A, Baboota S, Al J. Nanostructured lipid carrier system for topical delivery of terbinafine hydrochloride. Bull Fac Pharm Cairo Univ. 2015;53(2):147-59.

72 Butani D, Yewale C, Misra A. Topical amphotericin B solid lipid nanoparticles: design and development. Colloids Surf B Biointerfaces. 2016;139:17-24.

73 Jain K, Verma AK, Mishra PR, Jain NK. Characterization and evaluation of amphotericin $B$ loaded MDP conjugated poly(propylene imine) dendrimers. Nanomedicine. 2015;11(3): 705-13.

74 Yang M, Xie S, Adhikari VP, Dong Y, Du Y, $\mathrm{Li}$ D. The synergistic fungicidal effect of lowfrequency and low-intensity ultrasound with amphotericin B-loaded nanoparticles on C. albicans in vitro. Int J Pharm. 2018;542(1-2): 232-41.

75 Williams AC, Barry BW. Penetration enhancers. Adv Drug Deliv Rev. 2012;64:128-37.

76 Kapoor MS, GuhaSarkar S, Banerjee R. Stratum corneum modulation by chemical enhancers and lipid nanostructures: implications for transdermal drug delivery. Ther Deliv. 2017;8(8):701-18.

77 Kováčik A, Kopečná M, Vávrová K. Permeation enhancers in transdermal drug delivery: benefits and limitations. Expert Opin Drug Deliv. 2020;17:145-55.

78 Alberti I, Kalia YN, Naik A, Bonny JD, Guy $\mathrm{RH}$. In vivo assessment of enhanced topical delivery of terbinafine to human stratum corneum. J Control Release. 2001;71(3):319-27.

79 Kreutz T, de Matos SP, Koester LS. Recent patents on permeation enhancers for drug delivery through nails. Recent Pat Drug Deliv Formul. 2020;13(3):203-18.

80 Traynor MJ, Turner RB, Evans CR, Khengar $\mathrm{RH}$, Jones SA, Brown MB. Effect of a novel penetration enhancer on the ungual permeation of two antifungal agents. J Pharm Pharmacol. 2010;62(6):730-7.
81 Vasudevan D, Rajan R. Effect of permeation enhancers on the penetration mechanism of transfersomal gel of ketoconazole. J Adv Pharm Technol Res. 2012;3:112.

82 Amra K, Momin M. Formulation evaluation of ketoconazole microemulsion-loaded hydrogel with nigella oil as a penetration enhancer. J Cosmet Dermatol. 2019;18(6): 1742-50.

83 Abadi D, Zderic V. Ultrasound-mediated nail drug delivery system. J Ultrasound Med. 2011;30(12):1723-30.

84 Pany A, Klang V, Brunner M, Ruthofer J, Schwarz E, Valenta C. Effect of physical and chemical hair removal methods on skin barrier function in vitro: consequences for a hydrophilic model permeant. Skin Pharmacol Physiol. 2019;32(1):8-21.

85 Sloat BR, Kiguchi K, Xiao G, DiGiovanni J, Maury W, Cui Z. Transcutaneous DNA immunization following waxing-based hair depilation. J Control Release. 2012;157(1):94102

86 Vogt A, Hadam S, Deckert I, Schmidt J, Stroux A, Afraz Z, et al. Hair follicle targeting, penetration enhancement and Langerhans cell activation make cyanoacrylate skin surface stripping a promising delivery technique for transcutaneous immunization with large molecules and particle-based vaccines. Exp Dermatol. 2015;24(1):73-5.

87 Shemer A, Gupta AK, Amichai B, Farhi R, Baran R, Daniel CR, et al. An open comparative study of nail drilling as adjunctive treatment for toenail onychomycosis $(*)$. J Dermatolog Treat. 2016;27(5):480-3.

88 Tyle P, Agrawala P. Drug delivery by phonophoresis. Pharm Res. 1989;6(5):355-61.

89 Mitragotri S. Sonophoresis: ultrasound-mediated transdermal drug delivery. Percutaneous penetration enhancers physical methods in penetration enhancement. Berlin, Heidelberg: Springer; 2017. p. 3-14.

90 Oberli MA, Schoellhammer CM, Langer R, Blankschtein D. Ultrasound-enhanced transdermal delivery: recent advances and future challenges. Ther Deliv. 2014;5(7):843-57.

91 Polat BE, Hart D, Langer R, Blankschtein D. Ultrasound-mediated transdermal drug delivery: mechanisms, scope, and emerging trends. J Control Release. 2011;152(3):33048.

92 Levy D, Kost J, Meshulam Y, Langer R. Effect of ultrasound on transdermal drug delivery to rats and guinea pigs. J Clin Invest. 1989;83(6): 2074-8.

93 Mitragotri S. Transdermal drug delivery using low-frequency sonophoresis. BioMEMS and biomedical nanotechnology. Boston, MA: Springer; 2006. p. 223-36.

94 Lopez RF, Seto JE, Blankschtein D, Langer R Enhancing the transdermal delivery of rigid nanoparticles using the simultaneous application of ultrasound and sodium lauryl sulfate. Biomaterials. 2011;32(3):933-41. 
95 Zaytsev SM, Svenskaya YI, Lengert EV, Terentyuk GS, Bashkatov AN, Tuchin VV, et al. Optimized skin optical clearing for optical coherence tomography monitoring of encapsulated drug delivery through the hair follicles. J Biophotonics. 2020;13(4): e201960020.

96 Merino V, Castellano AL, Delgado-Charro MB. Iontophoresis for therapeutic drug delivery and non-invasive sampling applications. Percutaneous penetration enhancers physical methods in penetration enhancement. Berlin, Heidelberg: Springer; 2017. p. 77-101.

97 Wu C, Jiang P, Li W, Guo H, Wang J, Chen $\mathrm{J}$, et al. Self-powered Iontophoretic transdermal drug delivery system driven and regulated by biomechanical motions. Adv Funct Mater. 2020;30(3):1907378.

98 Burnette RR, Ongpipattanakul B. Characterization of the permselective properties of excised human skin during Iontophoresis. J Pharm Sci. 1987;76(10):765-73.

99 Hoogstraate A, Srinivasan V, Sims S, Higuchi W. Iontophoretic enhancement of peptides: behaviour of leuprolide versus model permeants. J Control Release. 1994;31(1): 41-7.

100 Park J, Lee H, Lim GS, Kim N, Kim D, Kim YC. Enhanced transdermal drug delivery by sonophoresis and simultaneous application of sonophoresis and Iontophoresis. AAPS PharmSciTech. 2019;20(3):96.

101 Watanabe S, Takagi S, Ga K, Yamamoto K, Aoyagi T. Enhanced transdermal drug penetration by the simultaneous application of iontophoresis and sonophoresis. J Drug Deliv Sci Technol. 2009;19(3):185-9.

102 Le L, Kost J, Mitragotri S. Combined effect of low-frequency ultrasound and iontophoresis: applications for transdermal heparin delivery. Pharm Res. 2000;17(9):1151.
103 Nair AB, Kim HD, Davis SP, Etheredge R, Barsness M, Friden PM, et al. An ex vivo toe model used to assess applicators for the iontophoretic ungual delivery of terbinafine. Pharm Res. 2009;26(9):2194-201.

104 Kline-Schoder A, Le Z, Sweeney L, Zderic V. Optimization of ultrasound-mediated drug delivery for treatment of Onychomycosis. J Am Podiatr Med Assoc. 2019.

105 Hao J, Ghosh P, Li SK, Newman B, Kasting GB, Raney SG. Heat effects on drug delivery across human skin. Expert Opin Drug Deliv. 2016;13(5):755-68.

106 Szunerits S, Boukherroub R. Heat: a highly efficient skin enhancer for transdermal drug delivery. Front Bioeng Biotechnol. 2018;6: 15.

107 Migdadi EM, Donnelly RF. Microneedles for transdermal drug delivery. Imaging technologies and transdermal delivery in skin disorders. Wiley; 2019. p. 223-70.

108 Waghule T, Singhvi G, Dubey SK, Pandey MM, Gupta G, Singh M, et al. Microneedles: a smart approach and increasing potential for transdermal drug delivery system. Biomed Pharmacother. 2019;109:1249-58.

109 Sintov AC, Krymberk I, Daniel D, Hannan $\mathrm{T}$, Sohn Z, Levin G. Radiofrequency-driven skin microchanneling as a new way for electrically assisted transdermal delivery of hydrophilic drugs. J Control Release. 2003; 89(2):311-20.

110 Lee WR, Shen SC, Sun CK, Aljuffali IA, Suen SY, Lin YK, et al. Fractional thermolysis by bipolar radiofrequency facilitates cutaneous delivery of peptide and siRNA with minor loss of barrier function. Pharm Res. 2015; 32(5):1704-13.

111 Engelke L, Winter G, Engert J. Application of water-soluble polyvinyl alcohol-based film patches on laser microporated skin facilitates intradermal macromolecule and nanoparticle delivery. Eur J Pharm Biopharm. 2018;128:119-30.
112 Genina EA, Bashkatov AN, Dolotov LE, Maslyakova GN, Kochubey VI, Yaroslavsky IV, et al. Transcutaneous delivery of microand nanoparticles with laser microporation. J Biomed Opt. 2013;18(11):111406.

113 Genina EA, Svenskaya YI, Yanina IY, Dolotov LE, Navolokin NA, Bashkatov AN, et al. In vivo optical monitoring of transcutaneous delivery of calcium carbonate microcontainers. Biomed Opt Express. 2016;7(6):2082.

114 Belikov AV, Skrypnik AV, Shatilova KV, Tuchin VV. Multi-beam laser-induced hydrodynamic shock waves used for delivery of microparticles and liquids in skin. Lasers Surg Med. 2015;47(9):723.

115 Fang JY, Lee WR, Shen SC, Wang HY, Fang $\mathrm{CL}, \mathrm{Hu} \mathrm{CH}$. Transdermal delivery of macromolecules by erbium:YAG laser. J Control Release. 2004;100(1):75-85.

116 Song Y, Hemmady K, Puri A, Banga AK. Transdermal delivery of human growth hormone via laser-generated micropores. Drug Deliv Transl Res. 2018;8(2):450-60.

117 Weiss R, Hessenberger M, Kitzmüller S, Bach D, Weinberger EE, Krautgartner WD, et al. Transcutaneous vaccination via laser microporation. J Control Release. 2012; 162(2):391-9.

118 Schmitt L, Marquardt Y, Amann P, Heise R Huth L, Wagner-Schiffler S, et al. Comprehensive molecular characterization of microneedling therapy in a human three-dimensional skin model. PLoS One. 2018; 13(9):e0204318.

119 Dragicevic N, Maibach H. Combined use of nanocarriers and physical methods for percutaneous penetration enhancement. Adv Drug Deliv Rev. 2018;127:58-84.

120 Svenskaya YI, Talnikova EE, Parakhonskiy BV, Tuchin VV, Sukhorukov GB, Gorin DA, et al. Enhanced topical psoralen-ultraviolet A therapy via targeting to hair follicles. Br J Dermatol. 2020;182(6):1479-81. 